\title{
Role of Transesophageal Echocardiography in Perventricular Closure of Muscular Ventricular Septal Defect
}

\author{
${ }^{1}$ BPS Ghuman, ${ }^{2}$ Alok Kumar, ${ }^{3}$ Saajan Joshi, ${ }^{4}$ Gaurav Kumar, ${ }^{5}$ Vivek Kumar
}

\section{ABSTRACT}

Muscular ventricular septal defect (mVSD) transcatheter occlusion technique is an established and preferred treatment modality and has become an alternative to surgery under extracorporeal circulation. But in small infants with large size of delivery assembly vis-à-vis small size of vessel caliber, it becomes not only technically challenging, but also possesses serious procedure-related complications. Perventricular device closure of such VSD on beating heart is an alternative. In this study, we aimed to present the role of intraoperative transesophageal echocardiography (TEE) in successful perventricular closure of $\mathrm{mVSD}$ in a small infant.

Keywords: Amplatzer septal occluder, Muscular ventricular septal defect, Perventricular closure.

How to cite this article: Ghuman BPS, Kumar A, Joshi S, Kumar G, Kumar V. Role of Transesophageal Echocardiography in Perventricular Closure of Muscular Ventricular Septal Defect. J Perioper Echocardiogr 2018;6(1):25-28.

Source of support: Nil

Conflict of interest: None

\section{INTRODUCTION}

Ventricular septal defect closure by percutaneous transcatheter closure techniques is now an established and preferred technique for mVSD closure. ${ }^{1-7}$ However, small infants with low weight or poor vascular caliber percutaneous device closure can be technically difficult and may lead to serious vascular complications. Hybrid procedures in $\mathrm{mVSD}$ closure combine surgical exposure and device intervention. ${ }^{8}$ Intraoperative TEE plays an important role in such hybrid techniques. This report presents successful device closure of an mVSD by perventricular approach on beating heart using Amplatzer mVSD occluder device in a child 11 months old weighing $7 \mathrm{~kg}$ under continuous TEE guidance.

\footnotetext{
${ }^{1-5}$ Classified Specialist

${ }^{1-3}$ Department of Anesthesia and Intensive Care, Army Hospital (Research \& Referral), New Delhi, India

${ }^{4}$ Department of Cardiothoracic Surgery, Army Hospital (Research \& Referral), New Delhi, India

${ }^{5}$ Department of Pediatrics, Army Hospital (Research \& Referral) New Delhi, India

Corresponding Author: Alok Kumar, Classified Specialist Department of Anesthesia and Intensive Care, Army Hospital (Research \& Referral), New Delhi, India, Phone: +918146044104 e-mail: docsomi@yahoo.com
}

\section{CASE REPORT}

An 11-month-old female baby presented with failure to gain weight and recurrent respiratory infections; on physical examination, there was grade II/VI systolic murmur. Transthoracic echocardiography (TTE) revealed dilated left ventricle with $10 \mathrm{~mm}$ mid-mVSD (Fig. 1). There was no other associated cardiac anomaly. She was scheduled for perventricular closure of the mVSD on beating heart with a $12 \mathrm{~mm} \mathrm{mVSD}$ Amplatzer occluder device (AGA Medical Corporation, Golden Valley, Minnesota).

The procedure was successfully performed without any complications under balanced general anesthesia under continuous TEE monitoring. After median sternotomy, a purse-string suture was placed around the carefully chosen right ventricular (RV) puncture site as guided by TEE. The exact puncture site on free RV wall is important in this procedure which can be done by intraoperative TEE imaging. In this case, the puncture site on free RV wall was guided by producing gentle indentations on free RV wall by surgeon. At first, the distance of $\mathrm{mVSD}$ from the apex is measured in midesophageal (ME) 4-chamber view which gives the sagittal plane for puncture site on RV free wall. After this, the lateral to medial plane of puncture site was marked by guiding surgeon in transgastric mid-papillary short axis (TG SAX) view.

Injection heparin $1.5 \mathrm{mg} / \mathrm{kg}$ was given before the puncture was made. An 18-gauge needle was inserted in RV at the chosen site and a guide wire was passed through the VSD into left ventricular (LV) cavity under TEE guidance.

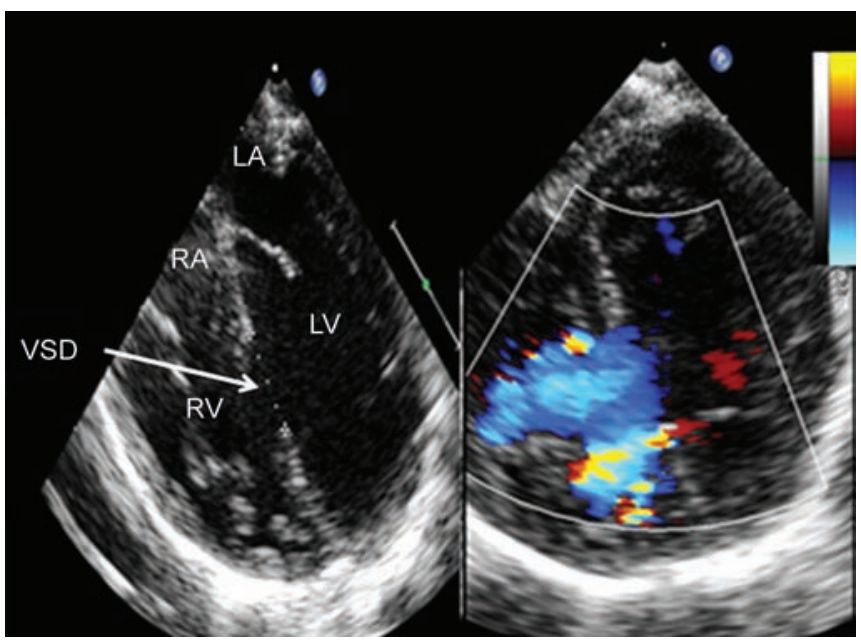

Fig. 1: Transesophageal echocardiography ME 4-chamber view: 13 $\mathrm{mm}$ mid-mVSD with left to right shunt. RA: right atrium; LA: left atrium 
An $8 \mathrm{~mm}$ Mullin short introducer sheath was passed over the wire into the LV cavity. The appropriate device size was chosen to be $2 \mathrm{~mm}$ larger than the VSD size as assessed by TEE. The device was advanced inside the short delivery sheath until it was seen by TEE to be close to the tip of the delivery sheath. The $12 \mathrm{~mm}$ device was introduced and LV disc was deployed in the mid-LV cavity. The sheath was withdrawn until the device was placed across the interventricular septum (Fig. 2). Continuous TEE to confirm the device position is of paramount importance. The TEE was performed to confirm device placement, assessment of residual shunting, and any obstruction or regurgitation induced by the device across tricuspid valve or mitral valve. Trachea was extubated after 2 hours and the child had uneventful recovery. On follow-up TTE before discharge, after 1 and after 3 months, there was no sign of shunt across the interventricular septum or device.

\section{DISCUSSION}

Conventionally, children with persistent small mVSD are subjected to percutaneous device closure at preschool age and the infants with large mVSD are managed surgically. ${ }^{9}$ Percutaneous transcatheter closure of mVSDs is a well-accepted procedure. Percutaneous closure of mVSDs in small infants with low weight is not only technically difficult but also imposes increased risk of procedurerelated complications due to relatively large delivery sheaths. ${ }^{3,4,6,7}$ However, the transcatheter closure using mVSD Amplatzer device also requires the use of large venous sheaths for device delivery, and exposes small infants to the risk of peripheral vascular injury and intervening cardiac structure damage. Although surgery is the preferred method, cardioplegic arrest and right ventriculotomy for mVSD may increase the chances of
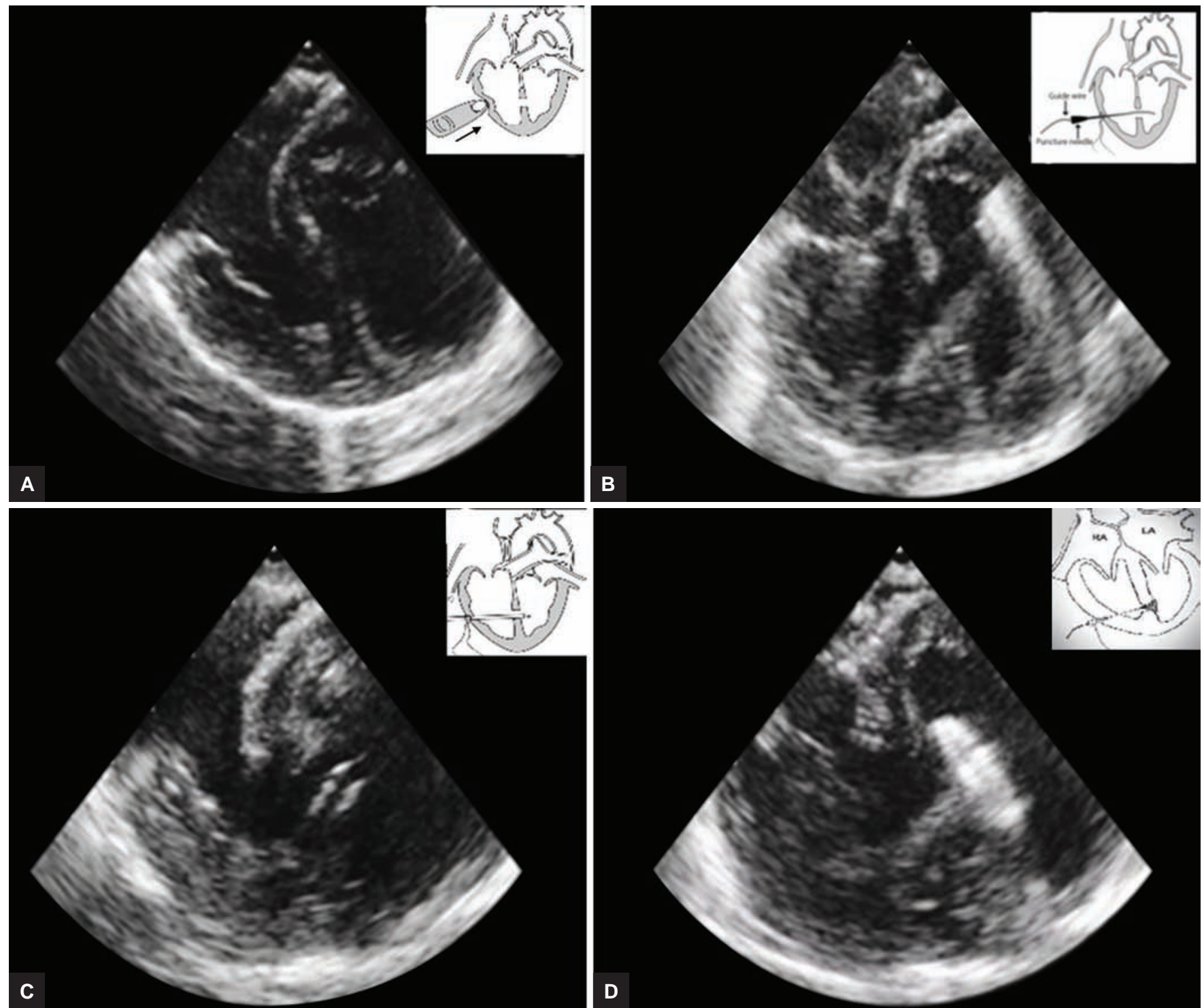

Figs 2A to D: General steps of perventricular device closure of VSD. Exposing and choosing the puncture site on the right ventricle. After surgical exposure of the anterior free wall of the right ventricle, the puncture site is identified by indenting the RV free wall under continuous TEE monitoring (A), to ensure that the puncture site is perpendicular to the defect and free of internal cardiac tissue. The guidewire is introduced into the RV and then through the defect to the LV (B). A delivery sheath is advanced into the LV over the guidewire (C). By pushing the device cable forward, the LV disk is deployed first (D) 

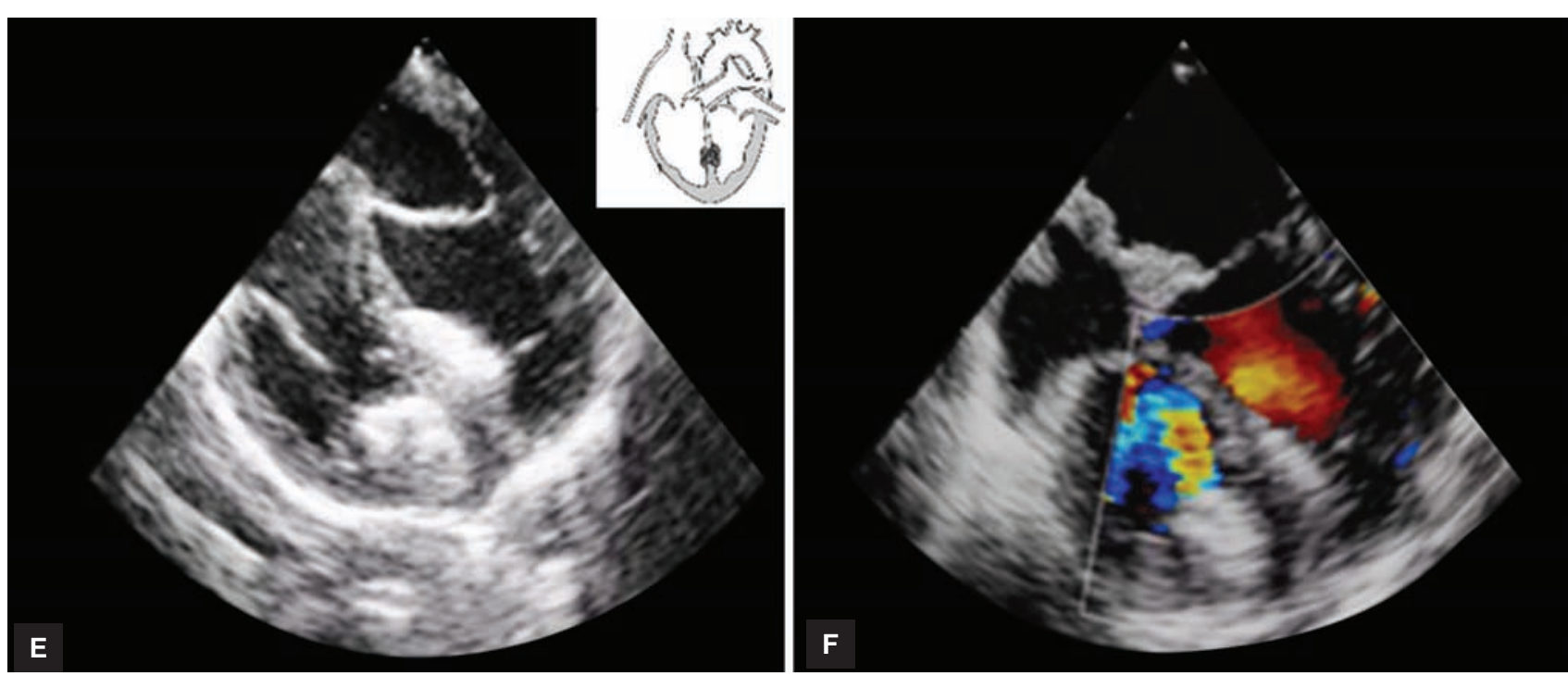

Figs 2E and F: Visualized by TEE. Then the waist and RV disk are subsequently deployed. Immediate postoperative assessment is done upon completion of device deployment, a TEE is used to detect valve dysfunction or residual shunt

complications associated with cardiopulmonary bypass, long procedure time, and ventriculotomy. Also the surgical approach from the right side of the heart does not allow for adequate visualization, and this is related to significant residual of the VSD shunt. ${ }^{10}$ An intraoperative perventricular procedure is a preferred option for closure of mVSDs in small children with or without associated cardiac anomalies. ${ }^{8}$

Because of its unique anatomy, $\mathrm{RV}$ requires multiple image planes for accurate marking of puncture site. The most useful TEE scan planes for RV include ME 4-chamber view, ME RV inflow outflow (ME RV IO) view, and TG SAX view. The ME 4-chamber view allows evaluation of apex, mid, and basal segments of RV free wall. The measured distance of mVSD from apex of the heart in this view guides the surgeon for the puncture site in sagittal plane using apex as the external landmark (Fig. 3A). The ME RV IO view is not helpful as it represents diaphragmatic portion of the RV wall and infundibulum. Also we cannot visualize mVSD in this view. The TG SAX view is obtained in horizontal scan plane with tip of the probe in stomach and anteflexed. Slight rightward rotation of the probe helps in viewing RV in center of the image screen. In this image, we can pinpoint the location of the puncture site from medial to lateral axis or transverse plane (Fig. 3B). Simultaneously keeping both the mVSD and indentation in RV free wall by surgeon in one image in two orthogonal planes will help in identification of correct placement of RV puncture.

Irrespective of weight, these infants can undergo perventricular VSD closure if they are not candidates for percutaneous approach. Large mVSDs can be closed successfully by a one-stage repair via sternotomy under continuous TEE guidance. ${ }^{11,12}$
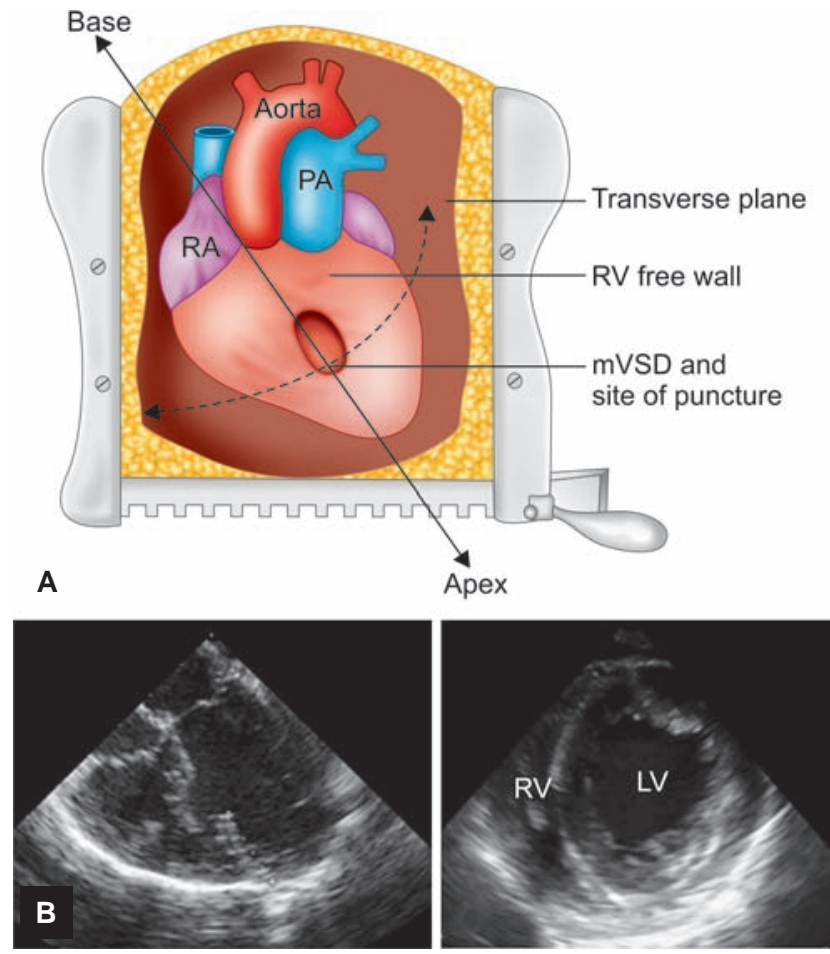

Figs $3 A$ and B: Schematic diagram showing RV free wall as seen after sternotomy. (A) TEE ME 4-chamber view and (B) TEE transgastric mid-papillary short axis view. RA: Right atrium; PA: Pulmonary artery

\section{CONCLUSION}

The TEE-guided perventricular device closure is a safe and effective method for closure of mVSDs. This hybrid technique under TEE guidance can be utilized to close mVSDs even in small babies without the need for exposure to X-rays.

\section{REFERENCES}

1. Myhre U, Duncan BW, Mee RB, Joshi R, Seshadri SG, HerreraVerdugo O, Rosenthal GL. Apical right ventriculotomy for closure of apical ventricular septal defects. Ann Thorac Surg 2004 Jul;78(1):204-208. 
2. Bridges ND, Perry SB, Keane JF, Goldstein SA, Mandell V, Mayer JE Jr, Jonas RA, Casteneda AR, Lock JE. Preoperative transcatheter closure of congenital muscular ventricular septal defects. N Eng J Med 1991 May;324(19):1312-1317.

3. Thanopoulos BD, Tsaousis GS, Konstadopoulou GN, Zarayelyan AG. Transcatheter closure of muscular ventricular septal defect occluder: initial clinical application in children. J Am Coll Cardiol 1999 Apr;33(5):1395-1399.

4. Hijazi ZM, Hakim F, Al-Fadley F, Abdelhamid J, Cao QL. Transcatheter closure of single muscular ventricular septal defects using the Amplatzer muscular VSD Occluder: initial results and technical considerations. Cathet Cardiovasc Interv 2000 Feb;49(2):167-172.

5. Bilgic A, Celiker A, Ozkutlu S, Ayabakan C, Karagoz T, Ocal T. Transcatheter closure of secundum atrial septal defects, a ventricular septal defect, and a patent arterial duct. Turk J Pediatr 2001 Jan-Mar;43(1):12-18.

6. Arora R, Trehan V, Thakur AK, Mehta V, Sengupta PP, Nigam M. Transcatheter closure of congenital muscular ventricular septal defect. J Interv Cardiol 2004 Apr;17(2):109-115.

7. Holzer R, Balzer D, Cao QL, Lock K, Hijazi ZM; Amplatzer Muscular Ventricular Septal Defect Investigators. Device closure of muscular ventricular septal defects using the Amplatzer muscular ventricular septal defect occluder. J Am Coll Cardiol 2004 Apr;43(7):1257-1263.

8. Amin Z, Gu X, Berry JM, Titus JL, Gidding SS, Rocchini AP. Perventricular closure of ventricular septal defects without cardiopulmonary bypass. Ann Torac Surg 1999 Jul;68(1):149-154

9. Serraf A, Lacour-Gayet F, Bruniaux J, Ouaknine R, Losay J, Petit J, Binet JP, Planché C. Surgical management of isolated multiple ventricular septal defects. Logical approach in 130 cases. J Thorac Cardiovasc Surg 1992 Mar;103(3):437-444.

10. Kirklin JK, Castaneda AR, Keane JF, Fellows KE, Norwood WI. Surgical management of multiple ventricular septal defects. J Thorac Cardiovasc Surg 1980 Oct;80(4):485-493.

11. Rodes J, Piechaud JF, Ouaknine R, Hulin S, Cohen L, Magnier $\mathrm{S}$, Lecompte $\mathrm{Y}$, Lefèvre T. Transcatheter closure of apical ventricular muscular septal defect combined with arterial switch operation in a newborn infant. Catheter Cardiovasc Interv 2000 Feb;49(2):173-176.

12. Bacha EA, Cao QL, Starr JP, Waight D, Ebeid MR, Hijazi ZM. Perventricular device closure of muscular ventricular septal defects on the beating heart: technique and results. J Thorac Cardiovasc Surg 2003 Dec;126(6):1718-1723. 